\title{
Population pharmacokinetics and optimization of the dosing regimen of digoxin in adult patients
}

\author{
Toshiaki Komatsu ${ }^{1 *}$, Mami Morita', Futaba Miyaji ${ }^{1}$, Takayuki Inomata ${ }^{2}$, Junya Ako $^{2}$ and Koichiro Atsuda ${ }^{1}$
}

\begin{abstract}
Background: This study aimed to evaluate the population pharmacokinetics of digoxin in Japanese patients and establish a dosage regimen based on the pharmacokinetic data.

Methods: We analyzed 287 serum digoxin samples from 192 individuals by using the nonlinear mixed effects model. We used simulations to optimize the dosage regimen of digoxin to achieve a high likelihood of the target concentration (0.5-0.8 ng/mL).

Results: The total body clearance $(C L / F([L / h])$ was calculated using the following formula: $C L / F=(1.21+0.0532 \times$ $\mathrm{CLCr}[(\mathrm{mL} / \mathrm{min}]) \times(1+0.787 \times \mathrm{AMD})$, where $\mathrm{CLcr}$ is the creatinine clearance and AMD is 0 in the case of concomitant administration of amiodarone and 1 otherwise. To achieve the target concentration $(0.5-0.8 \mathrm{ng} / \mathrm{mL})$, the dosage of digoxin was $0.0625 \mathrm{mg} /$ day $(\mathrm{CLCr}<35 \mathrm{~mL} / \mathrm{min}$ and $\mathrm{AMD}=0) ; 0.125 \mathrm{mg} / \mathrm{day}(\mathrm{CLcr}, 35-65 \mathrm{~mL} / \mathrm{min}$ and $A M D=0) ; 0.1875 \mathrm{mg} /$ day $(C L C r, 65-100 \mathrm{~mL} / \mathrm{min}$ and $\mathrm{AMD}=0) ; 0.0625 \mathrm{mg} /$ every other day $(\mathrm{CLCr}<30 \mathrm{~mL} / \mathrm{min}$ and $\mathrm{AMD}=1)$; and $0.0625 \mathrm{mg} /$ day $(\mathrm{CLCr}, 30-85 \mathrm{~mL} / \mathrm{min}$ and $\mathrm{AMD}=1)$.
\end{abstract}

Conclusions: Our findings suggest that population parameters are useful for evaluating digoxin pharmacokinetics.

Keyword: Digoxin, Population pharmacokinetics, Dosage regimen

\section{Background}

Digoxin is widely prescribed for the treatment of congestive heart failure and atrial fibrillation. Therapeutic drug monitoring of digoxin is recommended because of its narrow therapeutic range $[1,2]$. Previous studies have reported several equations and nomograms to enable physicians to determine the appropriate dosage of digoxin for individual patients $[3,4]$. In addition, population pharmacokinetic data indicate that clearance of digoxin is influenced by demographic variables such as age, total body weight, and serum creatinine levels [5-7]. However, population pharmacokinetics have not been studied thus far to evaluate the influence of concomitant administration of drugs such as amiodarone, verapamil, and tolvaptan on relative digoxin clearance. Recently, the therapeutic range for digoxin in patients with heart failure with a normal sinus rhythm has been revised to a low and narrow range

\footnotetext{
* Correspondence: t.komatu@kitasato-u.ac.jp

'Department of Pharmacy, Kitasato University Hospital, 1-15-1 Kitasato,

Minami-Ku, Sagamihara, Kanagawa 252-0375, Japan

Full list of author information is available at the end of the article
}

$(0.5-0.8 \mathrm{ng} / \mathrm{mL})$ based on the findings from the digitalis investigation group trial [8]. In this study, we aimed to analyze the population pharmacokinetics of digoxin in the presence of concomitant administration of other drugs. Furthermore, we determined initial dosing regimens to achieve concentrations $(0.5-0.8 \mathrm{ng} / \mathrm{mL})$ according to our population pharmacokinetic data.

\section{Methods \\ Ethics statement}

Blood samples were collected as part of the routine patient care for therapeutic drug monitoring and laboratory testing when we collect blood samples from patients. This study was approved by the Ethics Committee of Kitasato University Hospital (B13-99: approved on July 24, 2013).

\section{Data source}

Routine clinical pharmacokinetic data (287 observations) were retrospectively collected from 192 adult patients who were administered digoxin (Digosin'; Chugai Pharmaceutical Co. Ltd, Tokyo, Japan or Digoxin-KYं; 
Toaeiyo Pharmaceutical Co Ltd, Tokyo, Japan) at Kitasato University Hospital between November 2011 and January 2013. The clinical characteristics of patients in this study were shown in Table 1 . The patients were inpatients and outpatients. Inpatients were under the supervision of medical and nursing staff. As for outpatients, we checked their doctor's or nurse's medical records for patients' compliance and digoxin trough concentration samples. If this information wasn't written in medical records, the patient was excluded. Compliance was standardized, and digoxin concentrations were determined. Blood samples were obtained before the administration of the medication. Patient information is provided in Table 1 . The collected data included age, gender, height, body weight (BW), serum creatinine level, creatinine clearance (CLcr), ejection fraction (EF), serum potassium level, concomitant medication, and serum concentration of digoxin. Concomitant medication

Table 1 Patient characteristics

\begin{tabular}{|c|c|}
\hline Number of Patients & 192 \\
\hline Gender (Male:Female) & $121: 71$ \\
\hline EF (\%) $(>=40:<40)$ & $156: 36$ \\
\hline Age (year) & $71 \pm 12^{*}$ \\
\hline $\operatorname{CLCr}(\mathrm{mL} / \mathrm{min})$ & $56.17 \pm 33.76^{*}$ \\
\hline Weight (kg) & $55.47 \pm 11.94^{*}$ \\
\hline Observation & 287 \\
\hline $0.125 \mathrm{mg} / 3$ days & 7 \\
\hline $0.125 \mathrm{mg} / 2$ days & 17 \\
\hline $0.0625 \mathrm{mg} /$ day & 14 \\
\hline $0.125 \mathrm{mg} /$ day & 200 \\
\hline $0.25 \mathrm{mg} /$ day & 49 \\
\hline Digoxin concentration $(\mathrm{ng} / \mathrm{mL})$ & $0.90 \pm 0.56^{*}$ \\
\hline \multicolumn{2}{|l|}{ Combination medication } \\
\hline Amiodarone & 15 \\
\hline Amlodipine & 21 \\
\hline Atorvastatin & 14 \\
\hline Azelnidipine & 13 \\
\hline Bisoprolol & 28 \\
\hline Carvedilol & 53 \\
\hline Nifedipine & 13 \\
\hline Spironolactone & 35 \\
\hline Tolvaptan & 8 \\
\hline Antiarrhythmic agent; Class I & 12 \\
\hline \multicolumn{2}{|l|}{$\begin{array}{l}\text { (Aprindine, Cibenzoline, Flecainide, } \\
\text { Pilsicainde, Procainamide) }\end{array}$} \\
\hline Antiarrhythmic agent;Class IV & 31 \\
\hline (Bepridil, Diltiazem, Verapamil) & \\
\hline
\end{tabular}

*Mean \pm standerd deviation

EF; Ejunction function, CLcr; Creatine clearance xadministrated in the previously reported to influence digoxin pharmacokinetics were investigated. CLcr was estimated from the serum creatinine level using the CockcroftGault method [9]. One week after administration of digoxin, steady-state concentrations were achieved; subsequently, we drew blood samples before the morning dosing for the assay. The concentration of digoxin was measured using a cloned enzyme immunoassay. The minimum detectable concentration for digoxin was $0.2 \mathrm{ng} / \mathrm{mL}$. The coefficients of variation of both intra- and inter-assay precision were less than $10 \%$. The present study excluded patients who had any major disorders of the hepatic, gastrointestinal, dialysis or rapidly deteriorating renal function.

\section{Pharmacokinetics model}

Data analysis was performed using the nonlinear mixed effects model (NONMEM) program (version VI, level 1.0) developed by Beal and Sheiner [10]. Because the trough serum concentration of digoxin achieved steady-state, we used a simple pharmacokinetic model as follows: Cssij= $\mathrm{Dij} /(\mathrm{CLij}$ tij), where Cssi is the steady-state serum digoxin concentration measured in the jth patient while he or she received the ith dosage, $\mathrm{Dij}$ is the dosage of digoxin in the jth patient, CLij is the total body clearance of digoxin in the jth patient, and tij is the dosing interval for the ith dosage in the jth patient. We used the first-order conditional estimation method (FOCE) for modeling. The inter-individual variability of the parameters was assessed using an exponential error model: $\mathrm{Pi}=\mathrm{TV}(\mathrm{Pi}) \times \exp (\eta \mathrm{i})$, where $\mathrm{Pi}$ indicated the individual value, TV(Pi) was the population value for the parameters described in the equation, and $\eta \mathrm{i}$ was the random deviation of $\mathrm{Pi}$ from $\mathrm{TV}(\mathrm{Pi})$. The value of $\eta \mathrm{i}$ was assumed to be independently and normally distributed with a mean of 0 and a variance of $\omega 2$. The residual (intraindividual) variability of the parameters was assessed using a proportional error model: Cobs, $\mathrm{ij}=\mathrm{Cpred}, \mathrm{ij} \times(1+\varepsilon \mathrm{ij})$, where Cobs,ij and Cpred,ij denote the $j^{\text {th }}$ observed and predicted concentrations for the $\mathrm{i}^{\text {th }}$ subject, respectively, and $\varepsilon$ is a random intra-individual error that is normally distributed with a mean of 0 and variance $\sigma 2$.

\section{Covariate analysis}

We examined the covariance of the variables, including age, CLcr, BW, EF, systolic blood pressure, and concomitant use of drugs to improve the population pharmacokinetic model. The influence of continuous covariates on the pharmacokinetic parameter TV $(\mathrm{P})$ was modeled according to the following equations: $\operatorname{TV}(\mathrm{P})=\theta \mathrm{p}+\theta \mathrm{c} \times$ (covariance), and $\operatorname{TV}(\mathrm{P})=\theta \mathrm{p} \times \theta \mathrm{c}^{\text {(covariance) }}$. The covariance that showed a correlation with the pharmacokinetic parameters was introduced into the model. The significance of the influence of covariates was evaluated by a change of $-2 \log$ likelihood (the minimum value of the objective function: $\mathrm{OBJ}$ ). An OBJ decrease of more than 3.84 from the basic structural 


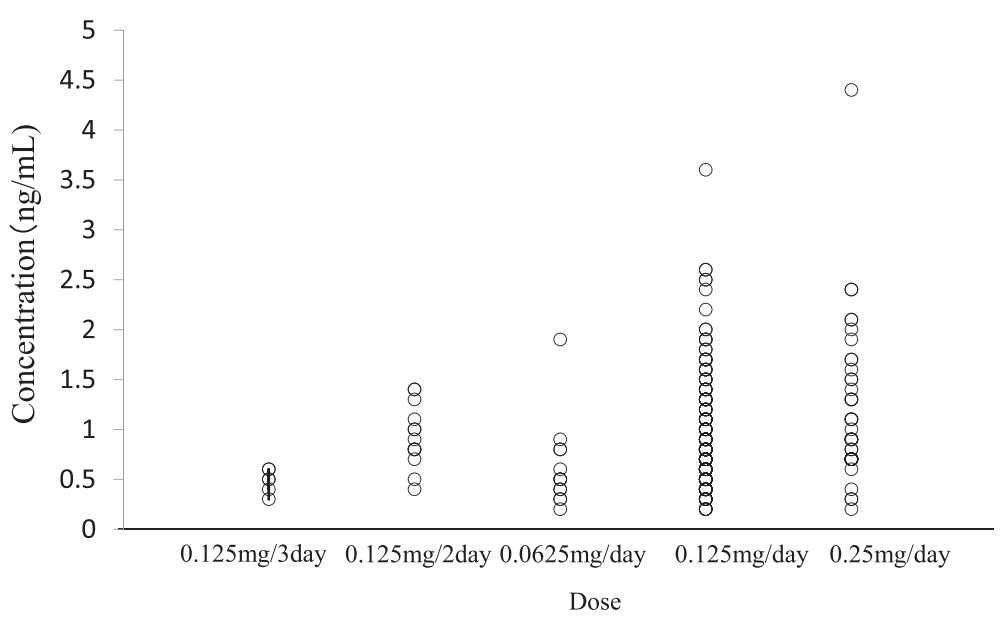

Fig. 1 Relationship between the dose of digoxin and serum concentration

model $(\chi 2$ : degree of freedom $=1, P<0.05)$ was considered statistically significant during the forward inclusion process. The full model was structured by incorporating the significant covariates, and the final model was developed using a backward elimination method. When one covariate factor was excluded from the full model, an OBJ that increased more than 6.63 from the full model $(\chi 2$ : degree of freedom $=1, P<0.01$ ) was considered statistically significant.

\section{Model evolution}

The adequacy of fitting was examined by plotting the predicted concentration versus the observed concentration, individual predicted concentration after Bayesian step versus observed concentration, and the weighted residual concentration versus the predicted one. The accuracy and robustness of the final model were assessed using the bootstrap method [11]. A bootstrap sample was generated by repeated random sampling of the original data set, and the size of the bootstrap sample was the same as that of the original sample. We reconstructed 200 bootstrap samples, and the final model was determined by repeatedly testing the 200 bootstrap samples. The mean parameter estimates obtained from replication and calculated normally were compared with those obtained from the original data set.

\section{Determination of the dosing regimen}

Simulation of pharmacokinetics was performed to determine the dosing regimen based on our population pharmacokinetics data. Digoxin concentration was simulated for 1000 patients by using the final population pharmacokinetics model.

The probability that the trough digoxin concentration was in the range of $0.5-0.8 \mathrm{ng} / \mathrm{mL}$ in the steady state was calculated as the ratio of the number of simulated patients to the total number of patients. The simulation was performed using Microsoft Excel $^{\circledR} 2013$.

\section{Results}

The serum concentration of digoxin as a function of the daily dose and each covariate model is shown in Fig. 1 and Table 2, respectively. CLcr, BW, amiodarone, amlodipine,

Table 2 Hypothesis testing for fixed effect model of digoxin pharmacokinetics

\begin{tabular}{|c|c|c|c|}
\hline Fixed model & OBJ & LLD & $p$-value \\
\hline$C L=\theta 1$ & -128.969 & & \\
\hline$\theta 1+\theta 2 \times C L C r$ & -331.151 & 202.182 & $<0.001$ \\
\hline$\theta 1+\theta 2 \times B W$ & -139.203 & 10.234 & $<0.002$ \\
\hline $\begin{array}{l}\theta 1 \times \theta 2^{\text {Ejection function }} \\
(E F>41=1, E F<40=0)\end{array}$ & -129.247 & 0.278 & N.S. \\
\hline$\theta 1 \times \theta 2^{\text {Age }}($ Age $>65=0$, Age $<64=1)$ & -131.508 & 2.539 & N.S. \\
\hline \multicolumn{4}{|l|}{$\begin{array}{l}\theta 1 \times \theta 2^{\text {Drug }}(0 ; \text { Cocomitant } \\
\text { adminstaraion, } 1 \text {;otherwise })\end{array}$} \\
\hline Amiodarone & -163.260 & 34.291 & $<0.001$ \\
\hline Amlodipine & -142.552 & 13.583 & $<0.001$ \\
\hline Atorvastatin & -135.985 & 7.016 & $<0.01$ \\
\hline Azelnidipine & -129.016 & 0.047 & N.S. \\
\hline Bisoprolol & -145.971 & 17.002 & $<0.001$ \\
\hline Carvedilol & -134.190 & 5.221 & $<0.05$ \\
\hline Nifedipine & -129.355 & 0.386 & N.S. \\
\hline Spironolactone & -132.177 & 3.208 & N.S. \\
\hline Tolvaptan & -133.804 & 4.835 & $<0.05$ \\
\hline $\begin{array}{l}\text { Antiarrhythmic agent;Class I } \\
\text { (Aprindine,Cibenzoline, } \\
\text { Flecainide,Pilsicainde,Procainamide) }\end{array}$ & -131.664 & 2.695 & N.S. \\
\hline $\begin{array}{l}\text { Antiarrhythmic agent;Class IV } \\
\text { (Bepridil,Diltiazem,Verapamil) }\end{array}$ & -131.559 & 2.590 & N.S. \\
\hline
\end{tabular}

$O B J$ the minimum value of objective function, $L L D-2$ log-likefood difference, N.S not significant 
Table 3 Final estimates for the population pharmacokinetic parameters of digoxin

Population mean parameters
$\quad \mathrm{CL}(\mathrm{L} / \mathrm{h})=(1.21+0.0532 \times \mathrm{CLCr}(\mathrm{mL} / \mathrm{min})) \times(1+0.787 \times \mathrm{AMD})$
$\quad(\mathrm{AMD}=0$ for cocomitant adminstarion of amiodarone, otherwise 1$)$
Interindividual variance
$\quad \omega(\mathrm{CL})=32.2 \%$
Intraindividual variance
$\sigma=25.5 \%$

atorvastatin, bisoprolol, carvedilol, and tolvaptan were significant covariates for the CL of digoxin. During the backward deletion from the full model, CLcr and amiodarone remained in the model that caused significant $\mathrm{OBJ}$ increase. Therefore, the final model was as follows: $\mathrm{CL} / \mathrm{F}(\mathrm{L} / \mathrm{h})=(1.21+0.0532 \times \mathrm{CLcr}[\mathrm{mL} / \mathrm{min}]) \times$ $(1+0.787 \times \mathrm{AMD})$, where $\mathrm{AMD}=0$ for concomitant administration of amiodarone or 1 otherwise.
The coefficient of variation $(\mathrm{CV})$ of the inter-individual variability $\left(\omega^{2}\right)$ of $C L$ and the residual variability $\left(\sigma^{2}\right)$ were 32.2 and $25.5 \%$, respectively (Table 3 ). Assessment of the predictive performance of the final model is presented in scatter plots of the observed concentration versus the population-predicted concentration (Fig. 2a) and the individual-predicted concentrations of digoxin (Fig. 2b). Weighted-residual concentration versus the population predicted concentration is shown in Fig. 2c. The plots were symmetrically distributed around the line of identity, which indicated that the model adequately described the serum concentration of digoxin. In the bootstrapping analysis of the final model, 180 of 200 showed successful results and the values of parameters used in the final model generated from the bootstrap analysis were similar to those of the developed model (Table 4).

We used the final model and performed a simulation to determine the dosing regimen in patients with renal impairment and in those with concomitant administration of amiodarone. Digoxin concentration
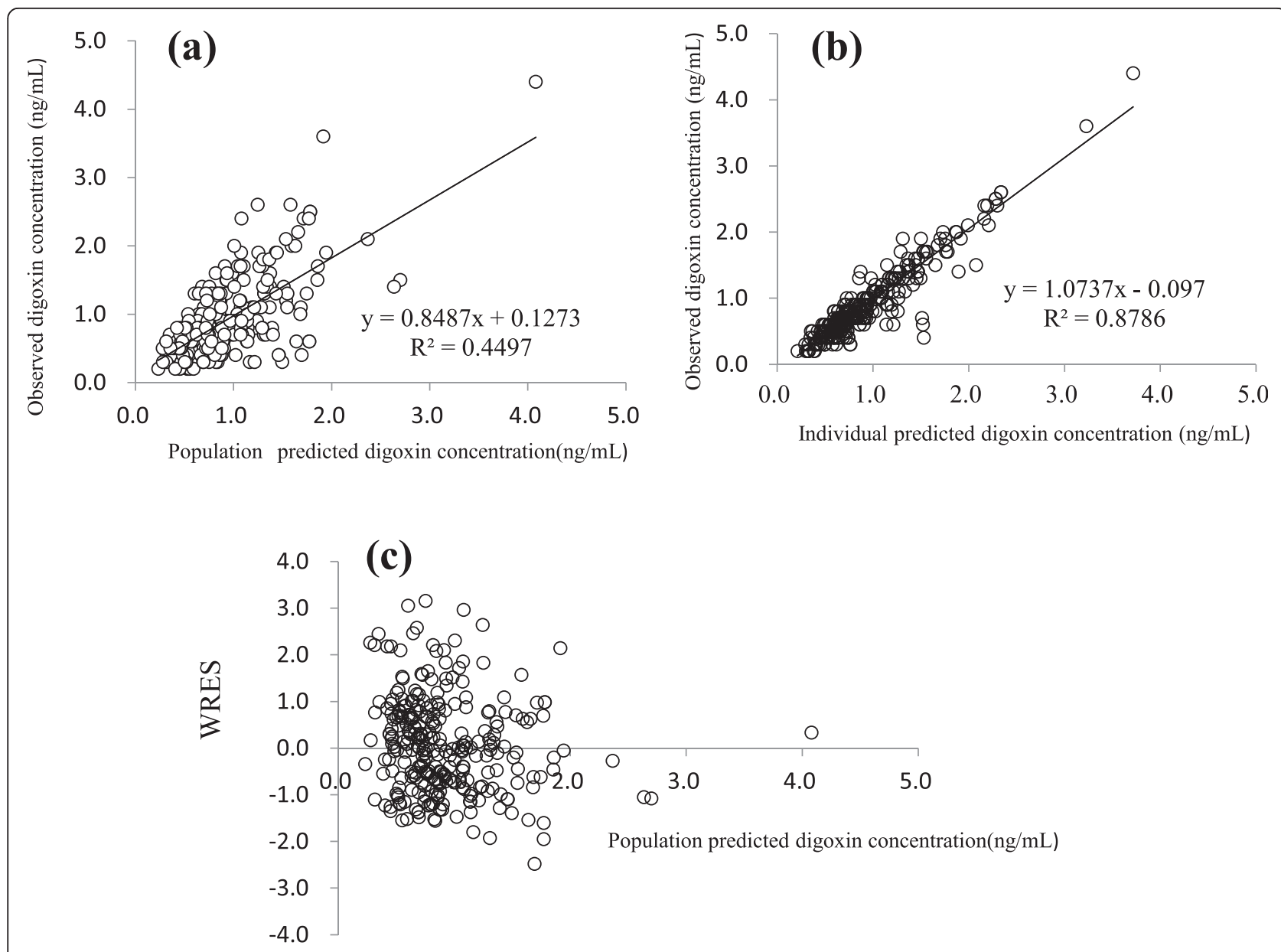

Fig. 2 a Population predicted concentrations from the final model; (b) Individual predicted concentrations from the final model. c Individual predicted concentrations from the final model. Scatter plot of weighted residuals (WRES) versus predicted concentration 
Table 4 Results of bootstrap validation

\begin{tabular}{llll}
\hline Parameter & $\begin{array}{l}\text { Final Model }^{\mathrm{a}} \\
\text { Mean } \pm \text { S.E. }\end{array}$ & $\begin{array}{l}\text { Bootstrap }^{\mathrm{b}} \\
\text { Mean } \pm \text { S.E. }\end{array}$ & $\begin{array}{l}\text { 95\% Confidence interval } \\
\text { [Lower, Upper] }\end{array}$ \\
\hline$\theta 1$ & $1.21 \pm 0.21$ & $1.30 \pm 0.05$ & {$[1.20-1.39]$} \\
$\theta 2$ & $0.0532 \pm 0.0068$ & $0.0543 \pm 0.0016$ & {$[0.050-0.057]$} \\
$\theta 3$ & $0.787 \pm 0.187$ & $0.803 \pm 0.018$ & {$[0.768-0.838]$} \\
$\omega C L$ & $0.104 \pm 0.017$ & $0.324 \pm 0.006$ & {$[0.312-0.336]$} \\
$\sigma$ & $0.065 \pm 0.010$ & $0.340 \pm 0.086$ & {$[0.171-0.509]$}
\end{tabular}

$\mathrm{CL}=(\theta 1+\theta 2 \times \mathrm{CLCr}) \times(1+\theta 3 \times \mathrm{AMD})$

a Obtained from the original data set

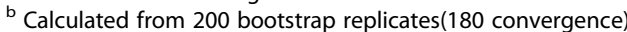

was simulated for 1000 patients with CLcr ranging from 5 to $130 \mathrm{~mL} / \mathrm{min}$ with or without amiodarone administration. The simulation was performed for dosages ranging from $0.0625 \mathrm{mg} /$ every 2 days to $0.25 \mathrm{mg} /$ day. The probabilities of trough digoxin concentrations being in the range of $0.5-0.8 \mathrm{ng} / \mathrm{mL}$ in the steady state are shown in Fig. 3. The typical initial dose of digoxin at various CLcr with or without amiodarone based on simulation experiments is shown in Fig. 4.

\section{Discussion}

To our knowledge, this is the first study in which a dosing regimen based on population pharmacokinetics has been proposed. We analyzed the sampling data for digoxin obtained from routine clinical data by using the NONMEM. This study focused on how drugs interact with digoxin. Our results showed that amiodarone and CLcr were significant covariants for the systemic clearance of digoxin. The systemic clearance consists of elimination rate constant and distribution volume. However, our model can't individually assess these parameters because our data is trough concentration sampling. The rate constant is mainly affected by creatinine clearance and amiodarone. Typically, digoxin is thought to be eliminated by the kidney. Additionally, previous studies showed that CLcr is an affective factor [5-7]. Regarding drug interactions, amiodarone, but not amlodipine, atorvastatin, bisoprolol, carvedilol, or tolvaptan, remained during the backward deletion. Beta blockers such as bisoprolol and carvedilol increase the maximum plasma concentration of digoxin by about 1.3-fold [12]. Similarly, administration of $10 \mathrm{mg}$ atorvastatin increases the maximum plasma concentration of digoxin by about
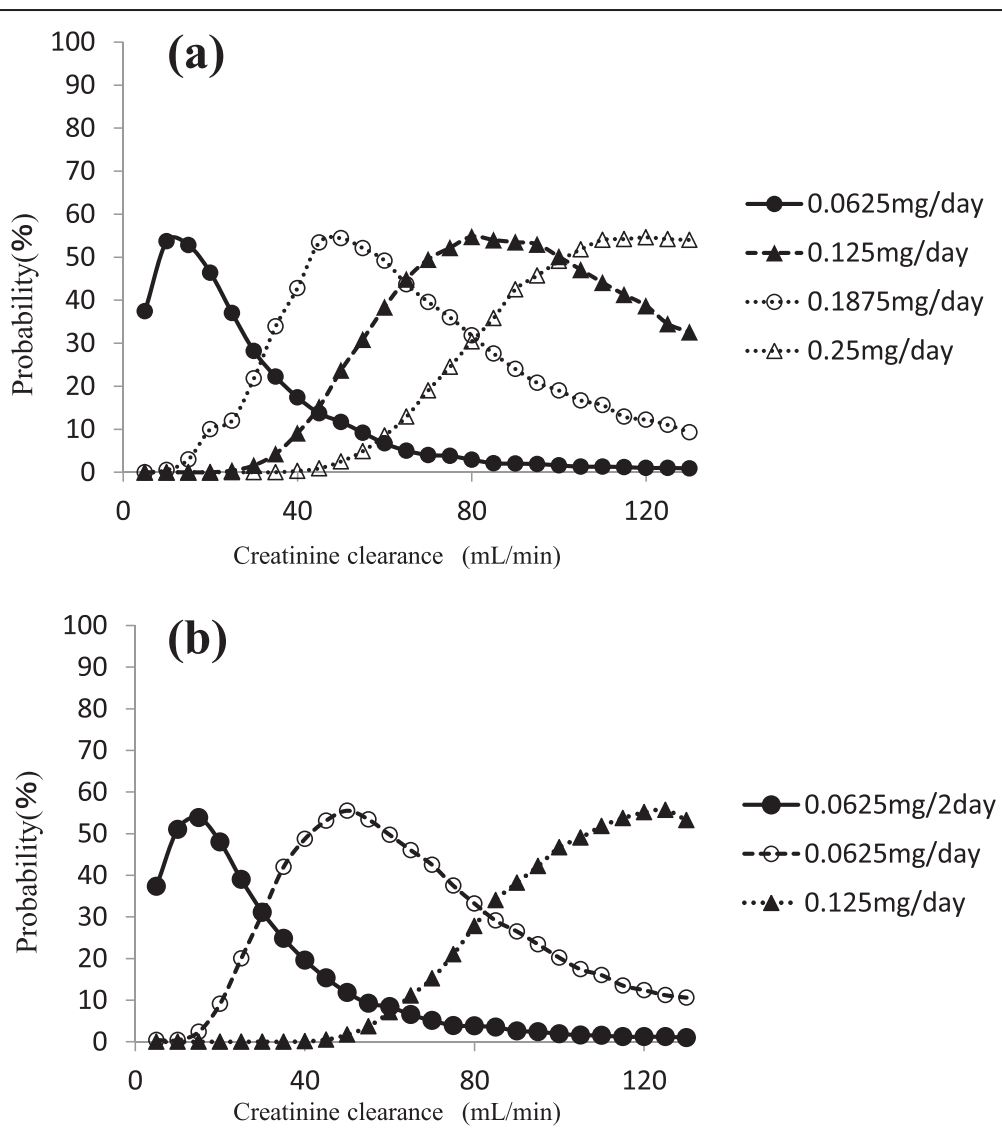

Fig. 3 Probability (\%) of trough concentration of digoxin being within $0.5-0.8 \mathrm{ng} / \mathrm{mL}$ at $\mathrm{CLcr}$ ranging from 5 to $130 \mathrm{~mL} / \mathrm{min}$ with amiodarone (a) or without administration (b) 


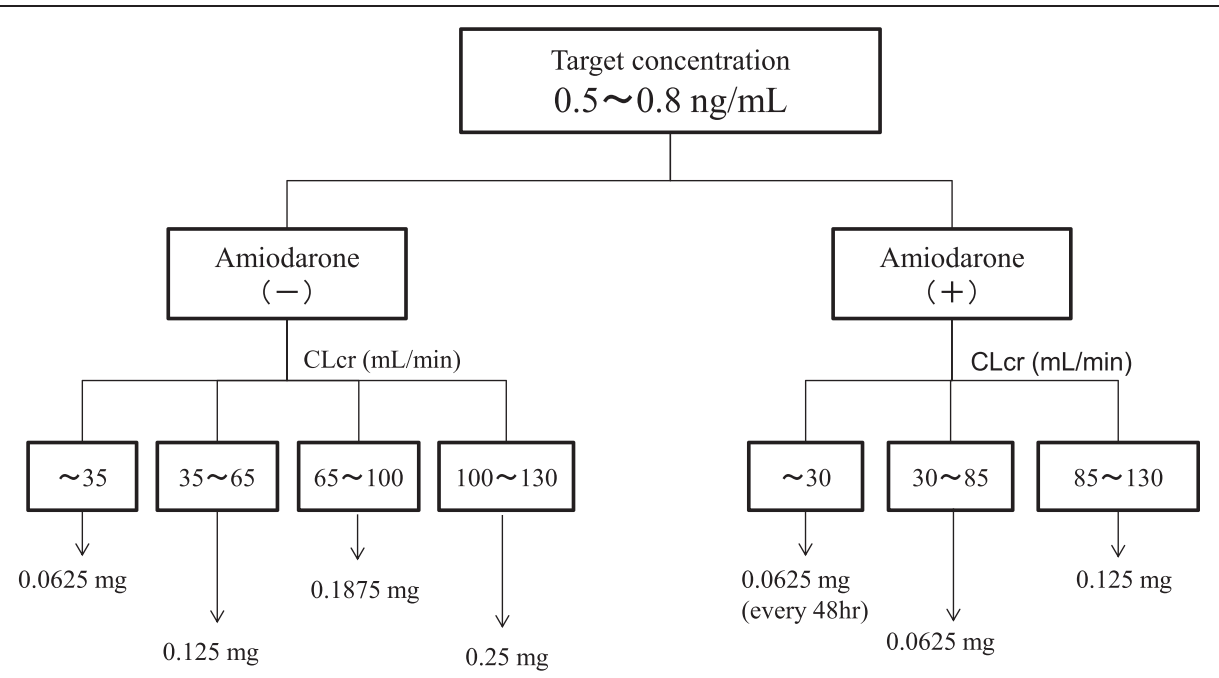

Fig. 4 Nomogram for target serum digoxin concentration. The proposed nomograms are presented as a target serum digoxin concentration of $0.5-0.8 \mathrm{ng} / \mathrm{mL}$

1.2-fold [13]. Administration of $60 \mathrm{mg}$ tolvaptan increases the maximum plasma concentration of digoxin by about 1.3-fold [14]. Schwartz JB reported that amlodipine does not significantly influence steady-state digoxin concentrations [15]. Chen $\mathrm{R}$ [5] and Yukawa E [6] showed that spironolactone and calcium channel blockers affect the clearance of digoxin. However these factors result in about a $20 \%$ decrease in digoxin clearance, and also these studies didn't examine amiodarone. Therefore, we concluded that these medications were not included as final factors. Amiodarone increased the trough level of digoxin concentration by approximately two-fold [16]. The main reason that amiodarone increases the serum concentration of digoxin is the inhibition of digoxin secretion from renal tubules and the inhibition of the P-glycoprotein membrane transporter system [17]. Our results showed that the population means showed a good predictive performance. The final model lacked bias, despite the drug concentration and the observed drug concentration being almost identical to the individual predicted concentration after the Bayesian steps. The weighted residuals were acceptable to within three standard deviations, which are generally recognized as criteria for no selection biases. In addition, the convergence ratio on bootstrap data was significantly high (Table 4). Thus, the robustness of the model was sufficiently confirmed. The difference between $\theta$ of the final model estimate and that of the bootstrap means was relatively small. Therefore, we concluded that the final model had a good predictive performance. In future studies, we will perform external validation for our new population pharmacokinetics model. The probability of the trough concentration of digoxin being in the therapeutic range of $0.5-0.8 \mathrm{ng} / \mathrm{mL}$ for congestive heart failure is shown in Fig. 3. This regimen suggests the typical initial dosage of digoxin in patients at various CLcr with co-administration of amiodarone. The different initial dosages of digoxin calculated using the Koup [18] and Jusko [19] method depending on different values of CLcr to achieve a target digoxin concentration of $0.7 \mathrm{ng} /$ $\mathrm{mL}$ were as follows: CLcr $<30 \mathrm{~mL} / \mathrm{min}$, start at $0.0625 \mathrm{mg}$ every day; CLcr $30-80 \mathrm{~mL} / \mathrm{min}$, start at $0.125 \mathrm{mg}$ every day; and CLcr $>120 \mathrm{~mL} / \mathrm{min}$, start at $0.25 \mathrm{mg}$ every day. In addition, Bauman JL et al [4] reported a nomogram for achieving a steady-state concentration of $0.7 \mathrm{ng} / \mathrm{mL}$ on the basis of creatinine clearance and IBW or height. These findings are similar to those obtained using our new dosing regimen without amiodarone. This initial dosage regimen will be useful for reasonable therapies using oral digoxin for congestive heart failure. Some limitations exist in this study. Some studies have shown that the serum concentration of digoxin increases after concomitant administration with other antiarrhythmic drugs such as verapamil and bepridil [20, 21]. We did not include these factors because very few patients in our study received concomitant administration of these drugs. Additionally, we didn't examine the effect of digoxin transportation role of P-glycoprotein inhibitors such as itraconazole, cyclosporine and clarithromycin [22-24] because these medicines are not administered. Therefore our nomogram is not adapted with concomitant with these medications. Our population model didn't consider volume of distribution or absorption phase. Therefore our model didn't simulate these phase. A prospective study using this regimen is necessary to investigate the robustness and reliability of our model. 


\section{Conclusion}

Our results suggested that these dosage regimens would provide maximum therapeutic benefit of digoxin, and achieve the overall goal of reducing the toxicity in patients in whom the dosage of digoxin exceeds the therapeutic range.

\section{Competing interests}

The authors declare that they have no competing interests.

\section{Authors' contributions}

TK and HM wrote the manuscript. TK, TI, JA, and KA designed the study. TK and MM analyzed data. All authors read and approved the final manuscript.

\section{Authors' information}

TK, MS, MM, FM, MS and AT, PD is a Department of Pharmacy of Kitasato University Hospital. TI, MD, is a lecture of Department of Cardiovascular Medicine, Kitasato University School of Medicine. JA, MD, is a professor of Department of Cardiovascular Medicine, Kitasato University School of Medicine.

\section{Acknowledgments}

We thank Kazuo Yago, Ph.D., for his support in this study. We would like to thank all the staff members of Kitasato University Hospital involved in this study.

\section{Author details}

'Department of Pharmacy, Kitasato University Hospital, 1-15-1 Kitasato, Minami-Ku, Sagamihara, Kanagawa 252-0375, Japan. ${ }^{2}$ Department of Cardiovascular Medicine, Kitasato University School of Medicine, Sagamihara, Japan.

Received: 1 May 2015 Accepted: 13 August 2015

Published online: 25 September 2015

\section{References}

1. Wagner JG. Appraisal of digoxin bioavailability and pharmacokinetics in relation to cardiac therapy. Am Heart J. 1974;88:133-8.

2. Mooradian AD. Digitalis. An update of clinical pharmacokinetics, therapeutic monitoring techniques and treatment recommendations. Clin Pharmacokinet. 1988;15:165-79.

3. Jelliffe RW, Brooker G. A nomogram for digoxin therapy. Am J Med. 1974:57:63-8.

4. Bauman JL, DiDomenico RJ, Viana M, Fitch M. A method of determining the dose of digoxin for heart failure in the modern era. Arch Intern Med. 2006;166:2539-45.

5. Chen R, Zou SL, Wang ML, Jiang Y, Xue H, Qian CY, et al. Population pharmacokinetics of digoxin in elderly patients. Eur J Drug Metab Pharmacokinet. 2013;38:115-21.

6. Yukawa E, Suematu F, Yukawa M, Minemoto M, Ohdo S, Higuchi S, et al. Population pharmacokinetics of digoxin in Japanese patients: a 2compartment pharmacokinetic model. Clin Pharmacokinet. 2001;40:773-81.

7. Yukawa E, Mine H, Higuchi S, Aoyama T. Digoxin population pharmacokinetics from routine clinical data: role of patient characteristics for estimating dosing regimens. J Pharm Pharmacol. 1992;44:761-5.

8. Rathore SS, Curtis JP, Wang Y, Bristow MR, Krumholz HM. Association of serum digoxin concentration and outcomes in patients with heart failure. JAMA. 2003;19:871-8.

9. Cockcroft DW, Gault MH. Prediction of creatinine clearance from serum creatinine. Nephron. 1976;16:31-41.

10. Beal SL. NONMEM User's Guides. San Francisco: NONMEM Project Group, University of California at San Francisco; 1992.

11. Ette El. Stability and performance of a population pharmacokinetic model. J Clin Pharmacol. 1997;37:486-95.

12. Wermeling DP, Field CJ, Smith DA, Chandler MH, Clifton GD, Boyle DA Effects of long-term oral carvedilol on the steady-state pharmacokinetics of oral digoxin in patients with mild to moderate hypertension. Pharmacotherapy. 1994;14:600-6.

13. Boyd RA, Stern RH, Stewart BH, Wu X, Reyner EL, Zegarac EA, et al. Atorvastatin coadministration may increase digoxin concentrations by inhibition of intestinal P-glycoprotein-mediated secretion. J Clin Pharmacol. 2000;40:91-8.

14. Shoaf SE, Ohzone $Y$, Ninomiya S, Furukawa M, Bricmont $P$, Kashiyama E, et al. In vitro P-glycoprotein interactions and steady-state pharmacokinetic interactions between tolvaptan and digoxin in healthy subjects. J Clin Pharmacol. 2011:51:761-9.

15. Schwartz JB. Effects of amlodipine on steady-state digoxin concentrations and renal digoxin clearance. J Cardiovasc Pharmacol. 1988;12:1-5.

16. Moysey JO, Jaggarao NS, Grundy EN, Chamberlain DA. Amiodarone increases plasma digoxin concentrations. Br Med J. 1981;24:272.

17. Yamreudeewong W, DeBisschop M, Martin LG, Lower DL. Potentially significant drug interactions of class III antiarrhythmic drugs. Drug Saf. 2003:26:421-38.

18. Koup JR, Jusko WJ, Elwood CM, Kohli RK. Digoxin pharmacokinetics: role of renal failure in dosage regimen design. Clin Pharmacol Ther. 1975;18:9-21.

19. Jusko WJ, Szefler SJ, Goldfarb AL. Pharmacokinetic design of digoxin dosage regimens in relation to renal function. J Clin Pharmacol. 1974;14:525-35.

20. Belz GG, Wistuba S, Matthews JH. Digoxin and bepridil: pharmacokinetic and pharmacodynamic interactions. Clin Pharmacol Ther. 1986;39:65-71.

21. Kuhlmann J. Effects of verapamil, diltiazem, and nifedipine on plasma levels and renal excretion of digitoxin. Clin Pharmacol Ther. 1985;38:667-73.

22. Partanen J, Jalava KM, Neuvonen PJ. Itraconazole increases serum digoxin concentration. Pharmacol Toxicol. 1996;79:274-6

23. Dorian P, Strauss M, Cardella C, David T, East S, Ogilvie R. Digoxincyclosporine interaction: severe digitalis toxicity after cyclosporine treatment. Clin Invest Med. 1988;11:108-12.

24. Tanaka H, Matsumoto K, Ueno K, Kodama M, Yoneda K, Katayama Y, et al. Effect of clarithromycin on steady-state digoxin concentrations. Ann Pharmacother. 2003;37:178-81.

\section{Submit your next manuscript to BioMed Central and take full advantage of:}

- Convenient online submission

- Thorough peer review

- No space constraints or color figure charges

- Immediate publication on acceptance

- Inclusion in PubMed, CAS, Scopus and Google Scholar

- Research which is freely available for redistribution

Submit your manuscript at www.biomedcentral.com/submit
C) BioMed Central 